\title{
Retrospectiva \\ Grafías, poéticas y cinematografías platónicas: Diez años del Grupo Élenchos-Philía
}

Prácticas de extensión 2012-2021

\author{
Cristian Emiliano Valenzuela Issac
}

CONICET-UBA

María Angélica Fierro

CONICET-UBA

Quizás sea por nuestro afán y nuestra amistad por lo antiguo que nos es natural dirigir el pensamiento hacia lo pasado, y así reconstruir y dar lugar en el presente a aquello que alguna vez sucedió, que regresa como imagen, como vivencia, como indicio (Ginzburg, 2004). Ya los griegos -aquellos griegos fundacionales en la historia de la filosofía occidental- se preocuparon por la inscripción de sus saberes con la convicción, y la ilusión, de que perdurarían por los siglos de los siglos. Ya Platón habría enlazado el ejercicio del recordar, y la facultad humana de la memoria, a uno de los mayores grados del conocimiento, y a su vez, a uno de los más grandes y poderosos impulsos humanos y universales: el amor (Fierro, 2020).

En esta oportunidad, deseamos rememorar parte de la historia de nuestro llamado Grupo Élenchos-Philía. Un grupo que ha sabido desarrollarse y crecer, enraizarse y prender, en los más diversos jardines de distintas casas de estudios. Un grupo que se originó hace más de 12 años, como brote de un seminario de grado dictado por la Dra. María Angélica Fierro para la carrera de Filosofía de la Universidad de Buenos Aires, que se dictó en el caluroso verano del año 2009. Un seminario en el que la tematización del éros platónico en los diálogos Banquete y República comenzó a trazar caminos y puentes nuevos que convocarían y se unirían en diversos proyectos.

Mas no nos detendremos aquí en la formación en investigación alrededor del élenchos (diálogo refutatorio socrático) que de la mano de María Angélica Fierro cosechamos en el marco de seminarios en la Sociedad Argentina de Análisis Filosófico (SADAF) y de distintos Proyectos de Reconocimiento Institucional de la Facultad de Filo- sofía y Letras de la UBA desde 2009 hasta 2012. Desplegaremos, a modo de cronología, en cambio, un ejercicio de retrospectiva hacia nuestras actividades de extensión, aquella práctica que se alza como uno de los pilares de las universidades modernas (Buchbinder, 2012), y que nuestro grupo, en donde fue esencial la entusiasta y permanente colaboración de Cristian Emiliano Valenzuela Issac, ha sabido diseminar a lo largo de la última década sin perder el carácter lúdico e itinerante que la misma filosofía platónica siempre nos ha enseñado. Cabe señalar que la inspiradora propuesta de Juan Jorge Michel Fariña y su equipo de entrelazar la reflexión filosófica y el cine, como un nuevo ropaje de la tragedia griega (Michel Fariña y Solbakk, 2012), fue frecuentemente motivo de inspiración y encuentro a lo largo de nuestro itinerario.

\section{2 - Esa chispa}

Nuestro primer taller en el marco de la Secretaría de Extensión Universitaria y Bienestar Estudiantil (SEUBE) en la Facultad de Filosofía y Letras (UBA) lo denominaríamos "Introducción a los diálogos socráticos de Platón", y a sala llena sostendríamos en la recóndita aula 131 del primer piso del edificio de la facultad el deseo y las ganas de acercarnos al método socrático a través escenas célebres de la narrativa platónica. Regresan a nuestra mente las distintas caracterizaciones de Sócrates que circulaban en el auditorio participante: el heroico, el mártir, el sabio, el feo, el pobre, el seductor. Y regresan los dibujos del filósofo que invitamos a realizar. Regresa, también, la luz del proyector evocando 
paisajes helénicos ante las representaciones teatrales de los diálogos. Y regresa el ritmo de la percusión corporal al son de aforismos pronunciados coralmente en griego antiguo. Esa chispa, en la que todo lo que vendría estaría concentrado.

\section{3 - El sabor de la palabra}

Reverdece en nuestra memoria nuestra primera participación en el Congreso Online de Ética y Cine mediante una reseña original sobre el film cubano Fresa y Chocolate (Gutiérrez Alea y Tabío, 1993), titulada "Encantamientos del paladar: banquete, fresa y chocolate" (Valenzuela Issac y Perrotti, 2013). Recuperar este trayecto nos permite descubrir el valor de aquellas otras artes que el filósofo posee además de la degustación de las palabras. Un encuentro incipiente entre cine y filosofía platónica, mas de ninguna manera insípido, en el que la fuerza de lo poético, del ensalmo y del bolero cubano auspiciaría un futuro prometedor.

Retorna, también de este año de intercambios con la Facultad de Psicología (UBA), el taller "Sofística, mayéutica y psicoanálisis. Reflexiones sobre el ejercicio del lenguaje" en el marco del V Congreso Internacional de Investigación y Práctica Profesional en Psicología. Nómades estudiantes y graduados/as en filosofía y psicología que decoraríamos un aula de la sede de la facultad de Psico en la Av. Independencia con pasajes platónicos y foucaultianos, en aquellas mismas paredes que oficiarían de sala teatral a la puesta en escena de una terapia de pareja entre Sócrates y Platón a cargo del Dr. Gorgias, especialista en el phármakon de la palabra. ¡Cómo no recordar ese señalamiento de un espectador, de que el Dr. Gorgias había emitido un fallido en plena escena confundiendo a Sócrates con Platón! Entre risas, vestimentas griegas y cruces entre la filosofía antigua y el psicoanálisis abriríamos caminos de promesa.

\section{4 - Alzar el vuelo}

Decantan nuestras experiencias en torno al élenchos socrático, la mayéutica y los cruces con el psicoanálisis en un Proyecto de Reconocimiento Institucional bianual titulado "El problema del élenchos socrático: su desarrollo en algunos diálogos platónicos y su influencia en la pedagogía y el psicoanálisis" (Res. CD N ${ }^{\circ}$ 1028/2015). De este modo, empezaríamos a arar un nue- vo territorio interdisciplinario, desde el que despegaríamos más de un vuelo en los años sucesivos.

\section{5 - Entre preguntas}

Frondoso año en el que Sócrates tomaría sus vestes de educador para permitirnos reflexionar sobre su figura claroscura como arquetipo pedagógico (Valenzuela Issac, 2015) encarnado en el film francés Entre les murs (Cantet, 2008). Año también en el que vería la luz un nuevo taller trimestral de extensión alojado por la SEUBE de la Facultad de Filosofía y Letras (UBA), entre las sillas en ronda de su aula de teatro, bajo el nombre de "La pregunta sobre el amor y el amor a las preguntas: una lectura del Banquete".

\section{6 - Semillero}

Ya un clásico de las tardecitas en Filo, esta vez entre las mesas de un aula laboratorio que la SEUBE nos asignara, discurriríamos nuevamente sobre el amor a través del taller trimestral "Filosofía, amor y encuentro en torno al Banquete de Platón", y experimentaríamos allí la escritura creativa y la articulación temática a partir del cruce de perspectivas que el film Una giornata particolare (Scola, 1977) nos permitiría. Nacerían escritos que habrían de quedar para semilla (Valenzuela Issac, 2016), que alcanzarían su esplendor durante el otoño venidero.

\section{7 - Retoños de sueños posibles}

Bautizaríamos con el nombre "Retoños de éros: grafías y cinematografías platónicas" (Fierro y Valenzuela Issac, 2017) a nuestra primera publicación grupal, gracias al apoyo y la valoración por parte del equipo editorial de la Revista Aesthethika. Revista internacional de estudio e investigación interdisciplinaria sobre subjetividad, política y arte perteneciente al Departamento de Ética, Política y Tecnología del Instituto de Investigaciones Psicológicas de la Facultad de Psicología (UBA). Allí desplegaríamos el juego de crear platónico (Fierro, 2017), desde nuevas lecturas en clave filosófica de nuestras clásicas películas Fresa y Chocolate (Gutiérrez Alea y Tabío, 1993) y Una giornata particolare (Scola, 1977), y de nuevas obras analizadas como Les amours imagi- 
naires (Dolan, 2016), The village (M. Night Shyamalan, 2004) y Sage femme (Provost, 2017), como así también desde la escritura filosófica en clave literaria, poética y performativa.

A su vez, durante este frondoso año, bajo el manto latiente del calor de la palabra sensible, aportaríamos un espacio lúdico a las V Jornadas de Estudiantes de Filosofía de la Universidad de Buenos Aires con una propuesta de taller denominada "Cuentos para soñar con Platón", en la que nuestros cruces se ampliarían hacia las narrativas de los cuentos "Nuestra Señora de las Golondrinas" (1982) de Margueritte Yourcenar, "Una bola de papel" (1968) de Dino Buzzati, y "La perla del amor" (1925) de Herbert Wells, desde donde volveríamos a sospechar de la condena a la poesía y del rechazo a la escritura atribuidos a Platón, temáticas que nos inquietan aún hoy, tan provocadoras por haber salido de su pluma, emergido de su palabra.

Por último, participaríamos nuevamente en el Congreso Online de Ética y Cine de la Facultad de Psicología de la UBA con una reflexión singular desde una ética platónica atenta a la corporalidad y a la belleza, que permite y habilita un pensar sobre la discapacidad (Fierro, 2017) desde el film argentino De eso no se habla (Bemberg, 1993).

\section{8 - Tiempos de cosecha}

Culminaría un ciclo de siembra con el balance del proyecto de investigación "El diálogo platónico como recurso del entrenamiento filosófico", desarrollado por Cristian Emiliano Valenzuela Issac y dirigido por María Angélica Fierro desde una Adscripción en la asignatura Historia de la Filosofía Antigua de la carrera de Filosofía (UBA). Un proyecto que contempló desde sus planteamientos iniciales una ecología de saberes (De Sousa Santos, 2010) que posibilitaría la participación de la comunidad en los dispositivos de taller impulsados en el marco de la extensión universitaria.

\section{9 - Una nueva estación}

Renacería la posibilidad de llevar adelante un taller de lectura del Banquete gracias a la SEUBE en la Facultad de Filosofía y Letras (UBA), en la misma aula 131 que nos habría alojado hacía un septenio, pero ahora bajo el nombre "El enigma del amor: una relectura del Banquete de Platón" Allí presentaríamos nuestro primer material didáctico hipermedial, que compila publicaciones de nuestro equipo y se propone como mediación digital y vehículo hacia la lectura del diálogo Banquete a través de las posibilidades que el territorio digital nos ofrece.

Brillaría también, en aquella primavera pre-pandémica, la experiencia del taller artístico-poético "Filoesía: el movimiento erótico como conciliador entre deseo filosófico y asombro poético", durante las VI Jornadas de Estudiantes de Filosofía organizadas por el Departamento de Filosofía (FFyL, UBA, 2019). Nos inspiraría en esta ocasión el sentipensar de la filósofa malagueña María Zambrano (1996) sobre los vínculos entre filosofía, poesía, pensar y poetizar, lo cual nos habilitaría una nueva lectura de Platón, además de la posibilidad de danzar sus conceptos en una caverna que reivindicara el valor de las sombras, del asombro.

\section{0 - Horizontes de noche}

Durante este año, de emergencia sanitaria y social, el frío invierno nos convocó, sin embargo, desde las posibilidades de las pantallas en las "Noches de amor, filosofía y vino: el mito de la media naranja en el Banquete platónico", ciclo organizado por María Angélica Fierro y Tomás Balmaceda en el marco de la Sociedad Argentina de Análisis Filosófico. A lo largo de tres reuniones, de la mano de provocadores/as, en un convite virtual de discursos, referencias literarias, cinematografías, historietas y ópera en vivo, invitaríamos a pensar, discutir y reflexionar a partir de la lectura y las apropiaciones del clásico mito aristofánico. Así, transmitiríamos por Youtube un encuentro colmado de antigüedad y actualidad en relación a las diversas formas de la orientación sexual, el carácter natural del amor libre, el poliamor, el sexo recreativo y el amor romántico.

Asimismo, el Congreso Online de Ética y Cine volvería a alojar una variedad de producciones de nuestro grupo (Alfonso, 2020; Dindurra, 2020; Feijóo y Sain, 2020) que echarían luz, desde una mirada platónica, sobre la corporalidad y el amor a partir de los films Non è mai troppo tardi (Campiotti, 2014), La ley del deseo (Almodóvar, 1987) y The half of it (Wu, 2020). Y volveríamos a proyectar aquella reflexión sobre la ética platónica y la discapacidad en el film De eso no se habla (Bemberg, 1993), esta vez mediante la participación de María Angélica Fierro en el Proyecto Deseo de cine. Ver y pensar películas y series en cuarentena. 


\section{1 - Amor itinerante}

Presentaríamos en las I Jornadas Festivar, en el marco del Festival de Proyectos Culturales con Impacto Social, y bajo el eje de Arte, género y diversidades, el Recursero, nuestro segundo objeto digital interactivo, que comprende los videos de las tres "Noches de filosofía, amor y vino", además de recursos textuales de autoría propia, recursos gráficos, recursos sonoros, links ampliatorios y espacios de debate y comunicación.

Y se gestaría, como último hito de nuestra historia aún abierta, el proyecto de extensión "Cinematografías platónicas: taller itinerante de cine-debate filosófico en torno a la corporalidad y el lenguaje", perteneciente al Grupo "Encarnación de saberes: conversaciones con la filosofía antigua", Programa Filosofía y Territorio del Departamento de Filosofía de la Universidad de Buenos Aires.

Las huellas de las imágenes que residen en nuestra memoria afloran al escribirnos, al pensarnos, permitiéndonos redescubrir esas señales y esos indicios fundantes de nuestra identidad como grupo de investigación, aprendizaje y extensión. Aquellos "vestigios, tal vez infinitesimales, que permiten captar una realidad más profunda, de otro modo inaferrable" (Ginzburg, 1989: 143).

Late aún aquel joven deseo, aquellas historias de amor que nos acompañaron con sus escenas una y otra vez, aquellas películas, aquellos cuentos, aquellas escenas, aquellos personajes, aquellos mitos. Late aún esa filosofía, que abraza y enlaza discursos, voces e instantes. Late aún la memoria, esta historia, y la que se escribirá.

\section{Referencias}

Alfonso, J. (2020) “Sujetos supuestos de aprendizaje”. En X Congreso Online de Ética y Cine. Facultad de Psicología. Universidad de Buenos Aires. https://www.eticaycine.org/El-maestro

Almodóvar, P. (director). (1987). La ley del deseo [película]. El Deseo, LaurenFilm S.A.

Bemberg, M.L. (directora). (1993). De eso no se habla [película]. Aura Film, Mojame S.A, Oscar Kramer S.A.

Buchbinder, P. (2012). ¿ Revolución en los claustros?: la reforma universitaria de 1918. Sudamericana.

Buzzati, D. (1968). Una bola de papel [Relato Corto]. Ediciones Arnoldo Mondadori.

Campiotti, G. (director). (2014). Non è mai troppo tardi [película]. BiBi Film, Radiotelevisione Italiana (RAI).

Cantet, L. (director). (2008). Entre les murs [película]. Haut et Court.

De Sousa Santos, B. (2010). Descolonizar el saber, reinventar el poder. Ediciones Trilce-Extensión universitaria Universidad de la República

Dindurra, D. (2020) “Las múltiples caras de éros”. En X Congreso Online de Ética y Cine. Facultad de Psicología. Universidad de Buenos Aires. https://www.eticaycine.org/La-ley-del-deseo-3602

Dolan, X. (director). (2010). Les amours imaginaires [película]. Alliance Atlantis

Feijóo, J. y Sain, A. (2020) “Amor y libertad”. En X Congreso Online de Ética y Cine. Facultad de Psicología. Universidad de Buenos Aires. https://www.eticaycine.org/The-Half-Of-It

Fierro, M. A. (2017) “De eso sí se habla: discapacidad y belleza a la luz de la ética platónica”. En VII Congreso Online de Ética y Cine. Facultad de Psicología. Universidad de Buenos Aires. https://www.eticaycine.org/De-eso-no-se-habla

Fierro, M. A. (2020). “Éros el memorioso”. Revista de Psicología (UNLP). https://revistas.unlp.edu.ar/revpsi/article/ view/10222/9692

Fierro, M. A. y Valenzuela Issac, C. E. (2017) (eds.). Número especial: “Retoños de Éros. Grafías y cinematografías platónicas”. Aesthethika. Revista internacional de estudio e investigación interdisciplinaria sobre subjetividad, politica y arte, 13(1). http://www. aesthethika.org/-Volumen-13-Numero-1-Especial-

Fierro, M.A. (2017), “Platón y el juego de crear” en Fierro M. A. y Valenzuela Issac, C. E. (eds.) Número especial: "Retoños de Éros. Grafías y cinematografías platónicas”. Aesthethika. Revista internacional de estudio e investigación interdisciplinaria sobre subjetividad, politica y arte, 13(1), 1-3. http://aesthethika.org/Platon-y-el-juego-de-crear

Ginzburg, C. (1989). "Indicios. Raíces de un paradigma de inferencias indiciales”. En Mitos, emblemas, indicios. Morfología e historia. Gedisa

Ginzburg, C. (2004). Tentativas. Protohistoria ediciones

Gutiérrez Alea, T. y Tabio, J.C (directores). (1993). Fresa y chocolate [película]. Miramax.

Michel Fariña, J. J. y Solbakk, J. H. (2012) “(Bio)ética: el cine como moderno teatro griego”. En (BIo)ética y cine. Tragedia griega y acontecimiento del cuerpo (pp.15-28). Letra Viva. 
Night Shuamalan, M. (director). (2004). The village [película]. Touchstone Pictures, Blinding Edge Pictures, Scott Rudin Productions.

Perrotti, N. y Valenzuela Issac, C. E. (2013) “Encantamientos del paladar: banquete, fresa y chocolate”. En III Congreso Online de Ética y Cine. Facultad de Psicología. Universidad de Buenos Aires. Disponible en: https://www.eticaycine.org/Fresa-y-chocolate

Provost, M. (director). (2017). Sage femme [película]. Curiosa Films, France 3 Cinéma, Versus Production.

Scola, E. (director). (1977). Una giornata particolare [película]. Compagnia Cinematografica Champion; Canalfox.

Valenzuela Issac, C. E. (2015) “Sócrates entre los muros de la escuela media: recepción del arquetipo pedagógico socrático en el film Entre les murs”. En IV Jornadas de Estudiantes de Filosofía de la Universidad de Buenos Aires. Facultad de Filosofía y Letras.

Valenzuela Issac, C. E. (2017), "Escritos que quedan para semilla: el aula platónica como terreno de fecunda filosofía” en Fierro M. A. y Valenzuela Issac, C. E. (eds.) Número especial: “Retoños de Éros. Grafías y cinematografías platónicas”. Aesthetbika. Revista internacional de estudio e investigación interdisciplinaria sobre subjetividad, politica y arte, 13 (1), 1-3. http://www.aesthethika. org/-Volumen-13-Numero-1-Especial-

Wells, H. (1925). La perla del amor [Relato Corto].

Wu, A. (directora). (2020). The half of it [película]. Likely Story.

Yourcenar, M. (1982). Nuestra Señora de las Golondrinas [Relato Corto].

Zambrano, M. (1996 [1977]). Filosofía y poesía. México: Fondo de Cultura Económica

\section{Materiales digitales}

Material didáctico hipermedial creado para el taller “El enigma del amor: una relectura del Banquete de Platón” (FFyL, SEUBE, 2019). Disponible en: https://view.genial.ly/5d371da614e5230fc30db28d/interactive-content-el-enigma-del-amor-una-relectura-del-banquete-de-platon

Recursero digital producido para el ciclo de provocaciones: "Noches de amor, filosofía y vino. El mito de la media naranja en el Banquete de Platón” avalado por la Sociedad Argentina de Análisis Filosófico. Julio de 2020. Disponible en: bit.ly/recurserobanquete 